Available online at www.jmle.org

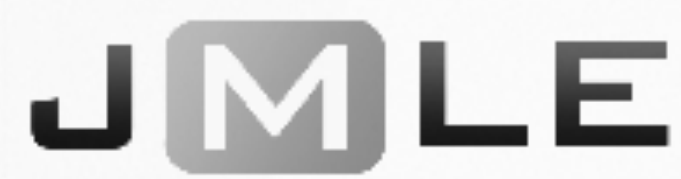

The National Association for Media Literacy Education's

Journal of Media Literacy Education 10 (1), 82 - 103

\title{
Youth and the City: \\ Reflective Photography as a Tool of Urban Voice
}

\author{
Roman Gerodimos \\ Bournemouth University, UK
}

\begin{abstract}
Young people's engagement with urban public space has been facing a number of obstacles that reflect a lack of understanding of their needs, values and priorities. The emergence of digital devices and social media as integral elements of youth culture adds further urgency to the need to understand how young people themselves visually articulate their perceptions of life in the city. Bringing together elements from urban studies, youth studies and digital media literacy, this paper puts forward a pedagogic and research approach that aims to facilitate youth engagement with urban landscapes and the community. Participatory photography was used a tool for capturing youth urban voice with British undergraduate students. A methodological framework for the coding and analysis of participants' images and reflective pieces was conducted with a pilot study involving 51 students. By employing a participatory/reflective photography methodology analyzing youth engagement with the urban landscape, the exercise produced highly engaged and emotive visual and textual narratives. Student work focused around issues of unemployment, dereliction and conglomeration. Findings reveal that participants focused more on the social and economic properties of place than on its aesthetic and architectural ones. They viewed their local spaces through media filters and a prism of disempowered and individualized consumption. The paper ultimately highlights a paradox: while young people are at the forefront of unprecedented global digital connectivity, at the same time their narratives emit a sense of civic loneliness. Global change and urbanization are perceived as destructive forces that have an adverse effect on their way of life.
\end{abstract}

KEYWORDS: cities, photography, writing, photovoice, urban landscape, young people, digital media literacy

As digital media have become integral to everyday life, a range of literacies have proliferated in the past few years aimed at equipping children and young people with key skills, such as critical evaluation, inquiry, analysis, and production for savvy media and information consumption (Friedman 2016; Mihailidis and Gerodimos, 2016). Digital media literacy is now widely recognized as a core competency for engaged citizenship in participatory 
democracy (Mihailidis and Thevenin, 2013). However, less attention has been paid to the spatial aspects of engagement and literacy (Leander, Phillips and Headrick Taylor, 2010). Place is socially constructed and, as such, carries and creates relations of power, which affect children and young people, perhaps even more acutely than adults (Massey, 1998, Kesby, 2007). This paper argues that navigating the urban environment should also be viewed as a key element of citizenship. Digital media and visual, digital and media literacies can be key facilitators of engagement with public space.

While dis/engagement - in particular of younger people - has been at the core of debates in political and youth studies, it is still considered as an underexplored theme in urban studies (Skelton, 2013). There is certainly a robust body of literature on the geographies of children and youth participation in planning (e.g. Skelton and Valentine, 1998, Skelton and Gough, 2013, Malone, 2002; Frank, 2006). However, young people continue to be systematically marginalized or excluded from urban space (Collins and Kearns 2001). They are considered to be either a risk to others, or at risk from others in public space (Brown, 2013).

Youth in the ages of 18-25 experience important life cycle transitions (e.g. moving out of their childhood home towns and going through college) while currently being at the generational, cultural and technological forefront of rapid global change. Globalization and in particular global economic restructuring have created particular challenges for young people - such as the privatization or reduction of open public space, disinvestment in infrastructure and local amenities, labor market changes and shifting attitudes towards surveillance and safety (Atkinson, 2003; Katz, 1998).

Younger people are most affected by the blurring of the boundaries between the public and private spheres, partly created by the increased presence and tethering of digital devices to our bodies (Turkle, 2011). Many technologies are seen as contributing to a 'privatism' of urban space (Lofland, 1998), while mobile media transform our understanding and engagement with place (Wilken, 2008: 40). The concerns about the privatization of public space (and, vice versa, about the publicness of private space - or, indeed, about mediated childhood and adolescence) are not new (Livingstone, 2005: 164), but youth engagement with such urban debates is still rare. In an age of increased virtuality, escapism and 'presentism', in what ways do young people engage and integrate with the fabric of urban community? How do they encounter and what is their perspective on memory, diversity, authority and control? As Brown notes (2013: 542), "[w]e need to appreciate more fully what public space means to young people, why they want to use it in certain ways and what this means for other users."

Working with children and young people and enabling them to explore and use the built environment as an arena for critical learning has multiple benefits: It aids their political socialization, understanding of cultural differences, and knowledge of local history, social issues and public affairs. It also allows them to become active observers and participants in the urban landscape, while also benefitting the community and the civic culture at large (Breitbart, 1995). Drawing on urban, youth and media studies, this paper (a) highlights the need for 
and value of engaging young people with local public space and specifically with emerging urban challenges; and proposes digital media literacy and participatory and reflective visual research as tools of doing that; (b) presents an original framework for the coding and analysis of participant-elicited photos and reflective pieces, grounded in debates about public space and the civic culture; (c) reports on the findings of a pilot study carried out with 51 student participants, who went out to their city, reflected on the challenges facing it, took a photo representing that challenge and then wrote a reflective piece. Each of these objectives is discussed in turn in the following sections.

\section{Research Context: Youth, Media and Public Space}

Place is a powerful agent of socialization - it functions as "the most powerful organizing theme of shared meaning" (Gordon and Koo, 2008: 205) and the relationship between self and place depends on "the accumulation of experiences, including complex social interactions, both with and within places" (Leyshon, DiGiovanna and Holcomb, 2013: 589). The spatial and social diffusion and embodiment of media, digital devices and social networks introduce a wealth of complexities, challenges and opportunities both for young people's engagement with each other, and for their engagement with the city itself. Mobile media transform our understanding of place (Wilken, 2008), while the ways in which we utilize mobile social networks introduces subtle but important changes to the ways we experience urban space (Humphreys, 2010).

Urban public space is critically important to young people; for many of them "the street is still the only autonomous space that they can carve out for themselves" (Gough and Franch, 2005: 156). Place - and play within place - are critical to children and young people's identity development (Skelton, 2013). The degradation of urban landscapes is not class-, gender-, race- or disability-neutral; it does not affect everyone equally. For example, children and young people from poorer backgrounds depend on their local spaces for vital amenities (Laughlin and Johnson, 2011: 453). And public space is not just streets, parks, fields. It is also local libraries, swimming pools, youth clubs, museums, learning spaces and meeting points.

Many scholars concur that youth voices are missing from policy, planning and even academic debates on the urban landscape. For example, "contemporary principles guiding public housing renewal do not match how young people interpret public space" (Laughlin and Johnson, 2011: 439). From the relatively sparse research into youth perceptions of urban landscapes, it has emerged that young people emphasize and appreciate aspects of public space that differ from the priorities or expectations of researchers, planners and decision-makers (e.g. Orellana 1999). Laughlin's and Johnson's study (2011) showed that young people predominantly emphasize social rather than physical solutions to urban problems, while their understanding of public space incorporates elements of quasi-public ("programmed") and even private spaces. Their key criteria are accessibility, sense of belonging and the ability to be with friends.

It is also necessary to address "the multifarious discursive processes and material practices" that shape their use of public space (Brown, 2013: 538). For 
example, one question is whether and how young people negotiate, internalize or challenge stereotypes and media frames about youth and the city- or, indeed, if they themselves feel threatened by others. One dominant stereotype views young people as potential troublemakers (a risk to others), as they are considered posing a threat to peace and order, while another one sees them as potential victims (at risk from others) (Matthews, Limb and Taylor, 2000; Laughlin and Johnson, 2011). In fact, the mere presence (or "hanging around on the street") of teenagers is mentioned as one of seven key variables of anti-social behavior in the British Crime Survey (Brown, 2013: 540). The Mosquito alarm, used in transport hubs and shopping malls across Britain and in other countries, emits sound at very high frequency that can only be heard by young people, so as to deter them from gathering or "loitering" in specific areas (BBC, 2011).

The increased use of surveillance systems, CCTVs, private security guards, fencing and other control measures means that public space is both materially and legally constructed in a way that makes it difficult for young people to be there without an apparent purpose. As Breitbart notes, "the reality of privately provisioned public spaces such as corporate plazas and small parks is that a considerable amount of control is exercised over who may occupy those spaces and how they may be used by privately hired security forces" (1998: 306307).

Furthermore, media and electronic devices are also often accused of making young people isolated, disengaging them from their surroundings, and encouraging them to spend more time in their own private comfort zone. As televisions, personal computers and video games gradually infiltrated their bedrooms, it looked as if young people were withdrawing from the city, spending less time with family, engaging in fewer physical activities, instead preferring to escape to virtual realities (Bovill and Livingstone, 2001). Previous studies on young people's media habits and the impact of media on their relationship to public space showed that when asked to "go unplugged" for a period of 24 hours (Gerodimos, 2016) or to "get lost on (or with a) purpose" (Leyshon, DiGiovanna and Holcomb, 2013), students reported discovering landscapes that they had not noticed before, re-engaging with their surroundings and for the first time being able to observe spaces and interact with other people.

The potential side effects of heavy media use should certainly not be overlooked; in fact, an increasing body of research has shown a link between problematic Internet use and poor quality of life, especially amongst children (Weinstein and Lejoyeux, 2010). However, factors such as depression, anxiety, low self-esteem and lack of social skills may actually be some of the causes of such increased media use, rather than merely the effects. Research on domestication and bedroom culture has shown that media and the privacy of the bedroom provide young people with a safe space in which they can explore their identities, experiment, follow their personal interests, understand their bodies and develop their individual self away from the pressures of peers and family (Livingstone, 2005: 170).

In fact, bedroom culture has developed partly because of the failures of a more public, outdoor leisure culture, in terms of access, cost and variety of 
activities (Bovill and Livingstone, 2001: 17). In other words, it is the condition of our cities and public space that may have forced young people to withdraw, rather than the other way around. Many young people choose to develop their identities and seek self-fulfillment in the comfort and safety of a private or virtual space, as opposed to a public one, precisely because "society offers them few alternatives" (Livingstone, 2005: 167) and some "still view the private as the only space in which to imagine any sense of hope, pleasure, or possibility" (Giroux 2011: 20).

The privatization of public space has led to "numerous struggles over the definitions of, and public access to, urban space" (Breitbart, 1998: 307). The creation of the High Line Park in New York City is a prominent example. Amanda Burden, New York City's planning commissioner from 2002 to 2013, who envisaged and led the creation of the High Line considers it "the most contested public space in the city" and revealed that she faced a daily battle against real estate developers and commercial interests who wanted to turn the space into a mall (Burden, 2014). Interestingly, these debates about the contestation of the physical public sphere mirror similar ones in media studies regarding the role of private interests and the commodification of digital culture. In fact, as digital media become more mobile and augment our relationship to physical reality, the two spheres have to be examined together. Hence, the role of digital media literacy as a core competency of civic engagement (Mihailidis and Thevenin, 2013) has to be extended to the realm of the spatial and the urban.

Even though previous research has succeeded in stressing the need to situate media literacy and youth engagement in their particular social, cultural and economic ecosystems, there has been less emphasis on these phenomena's physical, material and spatial aspects. The spaces, landscapes, artifacts and activities that young people engage through, with or in, or which surround and challenge them are fundamental components of the sociocultural ecosystem. In that sense, youth participation, media literacy and voice expression are often treated as abstract, virtual phenomena - a process for process's sake driven by a purely pedagogic agenda as opposed to socially embedded phenomena driven by real needs, thoughts and emotions situated in particular places Young people experience significant levels of mobility - educational, virtual and physical (Leander, Phillips and Headrick Taylor, 2010). Being able to navigate and interpret spaces and power relations requires a pedagogy that is equally flexible a classroom whose walls, as it were, are more permeable enabling students to engage with their environment (Sheehy, 2004). Finally, given the central role of visual media in contemporary youth culture, photography is an ideal tool of exploring these synergies. The ubiquitous youth practice of using mobile phones to snap photos and upload them on social media is creating new (visual) vernaculars - literally, new ways for young people to articulate and assert their civic voice.

\section{Reflective Photography as a Tool of Urban Voice}

Young people in their late teens and early 20s experience multiple transitions between school, university and work environments, as they move between communities that are very familiar to them and others that are completely 
new and possibly temporary. Despite the challenges facing youth engagement with the city, and the emerging role of media as a potent intervening variable, there seems to be a gap at the nexus of urban, youth and media studies. The literature on media literacy has not adequately examined the spatial implications and affordances of digital devices; the literature on youth studies could benefit from a more spatially grounded approach to civic engagement and voice expression; whereas the literature on urban youth has predominantly focused on children's geographies and youth needs. In order to address this gap, this paper puts forward a pedagogic and research approach that provides youth with the opportunity to reflect on the challenges facing their local community and captures these urban narratives through the use of digital media. Borrowing elements from urban environmental education, digital and media literacy, youth geographies, community engagement and political sociology, it attempts to create a space for the exploration and re-negotiation of public space, urban problems, and individual and collective identity.

The principal activities or steps of this framework involve students or other youth participants: (a) going out to their community and thinking about the key issues facing the local urban landscape (either through a predetermined sensory walk or through a more instinctive, random route - see Breitbart, 1995); (b) collecting visual artifacts and/or producing some form of multimedia that capture the problem or its effects on place (this could include photography and video or extend to a variety of other techniques, such as text messaging and diaries - see Leyshon, DiGiovanna and Holcomb, 2013); (c) writing a reflective piece that contextualizes the choice of issue and its representation through the chosen medium, as well as reflecting on the root causes and potential solutions and the role that digital and other media play. That last reflective step is crucial for the cognitive and emotional processing of all the stimuli that participants have been exposed to and the articulation of their voice.

The key concept of this assignment is that it encompasses all three elements - youth, media and urban public space - not as tangential components, but as co-creators of realities and identities. For example, not only are students invited to use media as practical tools for the recording of video or images, which in itself is key to the acquisition of media literacy skills (Paradise, 2011: 236), but they are also encouraged to reflect on wider debates regarding the role of media in creating, communicating or solving urban challenges, for example through representation, framing, stereotypes and awareness campaigns. From a media literacy perspective, asking students to take a photo encourages them to really look, observe and connect with their environment. In other words, the act of taking the photo itself can give participants a sense of belonging (Orellana, 1999). It also puts them in a situation of having to make a series of decisions about the subject matter, mis-en-scene, framing and aesthetics of their photo. That ability "to interpret, use, appreciate and create images and video using both conventional and 21 st century media in ways that advance thinking, decision making, communication, and learning" is at the heart of visual literacy (Burkhardt et al., 2003: 24 as cited in Friedman, 2016). 
The approach outlined here can have multiple potential benefits - for the young people involved, for research in the disciplines involved, and for the community. At a basic level, it encourages youth to explore their surroundings on foot and to be observant of spaces, landscapes and other people. It gives students who live away from home the opportunity to get to know their town a little better, and those who are familiar with the area to reconnect with or speak out regarding broader community issues. This is a vital element of community engagement courses and activities, as even basic research about the built environment "can have real-world applications that benefit individuals and organizations. [...] [P]lace-based learning gives students a unique opportunity to experience the 'messiness' of problem-solving" (Henthorn, 2014: 450; for a similar approach see also Mooney-Melvin, 2014).

The use of photography in social research has seen a healthy growth over the last few decades. Originally used as a tool of visual anthropology and visual sociology (i.e. archival research or photos taken by the researcher), it has evolved into techniques such as photo-elicitation (Harper, 2002) - i.e. using photographs during interviews so as to facilitate discussion and generate multidimensional narratives and more recently to the practice of handing over the cameras to the participants and asking them to take their own photos (e.g. Gotschi, Delve and Freyer, 2009). Different names have been used to describe this method: participatory (or reflective or reflexive or collaborative) photography, photovoice, autodriven photo elication, photo novella, etc. Each of these titles emphasises a different trait of the practice, but the basic process is usually similar; the principle of participatory photography is that "people are experts on their own lives" (e.g. Wang et al, 2004: 911).

As Meringolo (2014: 421) points out, many contemporary students tend to be visual thinkers and therefore "their preferences and skills are well suited to the study and analysis of urban environments"; at the same time, they may feel more at ease in virtual environments: "their experience in the digital realm has left many of them uncomfortable and unfamiliar with city neighborhoods, and ill prepared to explore human relationships". Therefore there is considerable margin for a transformative experience.

Reflective photography has numerous advantages: (a) it can convey nonverbal contents and trigger unforeseen interpretations; (b) it produces rich data that have an aesthetic and material dimension; (c) it captures an increasingly culturally dominant mode of human communication and self-expression; (d) it enhances participants' visual literacy skills; (d) it enables reflection which benefits the participant by allowing them to articulate their relationship to self, the familial and the social; (e) it treats research participants as "active, creative and important actors in their own right" (Clark-Ibanez, 2007) and therefore compensates for power imbalances that are inherent in the researcher-participant relationships (also see Samuels, 2007).

Despite the recent proliferation of digital technologies, visual research is still at the fringes of research practice: many scholars are unaware of the potential of visual methods, and there is a distinct lack of rigorous methodology and many studies fail to be specific about the quantitative or qualitative variables that they 
explored (Pauwels, 2011; Chalfen, 2011). This reinforces commonly held prejudices about the polysemic nature of images as data. Despite the ubiquity of visual or multi-platform communications, our analytical tools and mind-sets are still largely oriented towards a textual research culture. Part of the problem may lie with the perceived subjectivity of visual analysis, although as long as the research remains loyal to the principles of rigour, transparency and reflexivity, visual research can produce rich and unique insights.

Recent field-setting volumes have provided space for a discussion of ontological, epistemological and ethical dilemmas (Stanczak, 2007, Margolis and Pauwels, 2011, Hughes, 2012, Gubrium and Harper, 2013). Yet, there are still surprisingly few presentations of specific coding schemes (Bell 2012; and Bock, Isermann and Knieper, 2012 are two examples but both refer to the analysis of third-party images featuring in mass media rather than participatory photography). And while creative and participatory methods are increasingly used in research and literacy practice involving children (e.g. Friesem, 2014, Friedman, 2016), there are very few participatory photography studies involving teenagers and young people in their 20s (e.g. Orellana, 1999, Tunstall, Tapsell and House, 2004). Perhaps as importantly, most researchers treat photographs as a tool or excuse of facilitating interviews rather than as legitimate and valuable data worthy of primary analysis (see Clark-Ibanez, 2007, Orellana, 1999). In fact, there are no known studies employing a participatory/reflective photography methodology that focuses on youth engagement with the urban landscape and that provides a replicable coding/analytical framework.

This paper presents an analytical scheme incorporating both a structured and a more interpretive coding of images' features along with a thematic analysis of the reflective pieces accompanying the photographs. Thus images were not viewed in isolation but in conjunction with the rationale and context - of taking the photo itself, and of engaging with the issues and spaces - provided by the participants. Both parts of the coding scheme were initially designed with key concepts and debates surrounding urbanization, civic coexistence, public space, youth and media in mind, but they were also revised, enriched and fine-tuned by going through the material multiple times, in an iterative process akin to grounded theory.

Part of this process entailed "translating" or breaking down quite abstract debates into discernible objects or activities. In some cases this was reasonably straightforward, as in the case with the debate on the securitization of public space. As Brown (2013: 539) notes "[s]uch processes have manifested themselves in the material landscape in the form of things such as gates, fences, curved benches, closed circuit television operating systems and sprinkler systems which are all designed and used to exclude 'undesirable' groups from public space". In the case of more abstract concepts - such as linkages between the local, the national and the global - this was done through the more open-ended elements of the coding scheme.

The coding book for the photographs featured 130 categories, including basic properties of the image itself, evidence of diversity or homogeneity across a number of demographic characteristics, human activities represented (walking, 
resting, shopping etc), a wide range of public, private and industrial buildings and spaces, means of transport and communication, evidence of social control or boundaries (e.g. fences, guards, bollards, signs), typical elements of the urban (such as sewers, bins, benches, booths) and natural landscape (water, flowers, animals, birds etc) and architectural styles.

Beyond these descriptive elements it also provided space for the coders to identify themes related to the civic culture (memory, art, interaction), coexistence and social organization (inclusion v. exclusion, coming together v. isolation, good v. evil, victims and perpetrators) and the overall ambience of the landscape (on the axes of quiet/loud, clean/dirty, busy/empty). The coding book for the reflective pieces captured perceptions of space and the city (e.g. boundaries between public and private); activities and everyday routines associated with urban space; observations on urban and civic culture; perceptions of beauty and morality related to space; as well as registering the main challenges or problems that the participants chose to focus on; the perceived causes and social impact; links between the local, the national and the global; reflections on the perceived impact (if any) of the media in creating or solving the problem; and ideas for potential solutions, including the extent to which individual citizens are capable of - or even responsible to - being part of the solution. That part of the analysis also examined youth-specific observations, such as those relating to young people's identity (e.g. roots, values and choices), daily lives and repertoires of engagement, and the stereotypes or challenges they face. Finally, it also captured any stated pedagogic benefits or reflections about the process of engaging in this activity.

After an initial blind testing of the coding sheet on a subsample by two coders (93\% agreement), the coding book was further refined so as to enhance clarity. While intercoder reliability was not applicable to the qualitative analysis of the photos or the analysis of the reflective pieces, the author was assisted by two coders in crosschecking coding decisions and capturing themes and narratives. Developing a detailed quasi-quantitative framework to analyze photographs whose sophistication and artistic merit is bound to vary may appear excessive. Yet, a comprehensive structured coding scheme such as the one presented here can be a valuable first step in identifying common (or, indeed, diverse) themes and patterns across a sample, as well as in systematically capturing details that can then be further picked out through the textual analysis.

\section{Method}

Context. A pilot study involving 51 students was carried out at Bournemouth University, England, in October 2012. The study was run as part of the Media: Messages and Meanings module - a second-year media theory and media literacy course taught by the author, within the school's BA (Hons) Communication \& Media program. This optional co-curricular assignment was part of a broader international project - 'On Cities' - launched by university partners at the 2012 Salzburg Academy on Media \& Global Change. Student photos and reflections were exhibited online and offline during a global virtual gathering at the University of Miami. The gender skew of the sample $(88 \%$ 
female) reflects the demographic make-up of the program. While detailed data on the participants' ethnic background was not collected, as this was only a pilot qualitative study, the student cohort is predominantly of British origin.

Assignment. Students were instructed to go out to their town or city, reflect on the challenges facing it and take a photo (candid, portraits, illustrations or mixed media) representing an emerging urban problem. They were then asked to write a short (250-300 word) reflection on their experience. The instruction sheet included a few prompts for the reflective piece: the reason for choosing the particular setting; outlining the perceived problem, its causes, importance and consequences; people who are responsible for, or affected by, it; the role of the media; and possible solutions. Participation in the study was entirely voluntary and while students were encouraged to complete it as part of their curricular experience, it was not linked to their grading in any way.

In contrast to many creative research and literacy studies involving photography, students were not provided with cameras and they were not given advice or training on photography. The point of this particular pilot was not to incorporate this exercise within a broader curriculum of technical savvy or to standardize their output, but to capture the existing modes of their visual expression and photographic practice - i.e. the type of images they might take themselves using the devices they normally use to take photos. Students did not appear in the photos and they were advised not to take close-ups of other people unless they had their express permission.

Despite the relative simplicity of the task, this act of mindful engagement produced a torrent of emotional narratives, as students ended up writing highly passionate commentaries that often went well beyond the stated word limit. The exercise unlocked young people's voice and allowed them to express their concerns. The photos and reflective pieces produced by students highlight a range of issues and phenomena - social, economic, environmental, lifestyle and some location-specific.

Locations. It should be noted that the aim of this study was not for students to engage with one particular community - such as the town of Bournemouth that their university is located at - but with an urban setting of their choice. As it turned out, 33 participants chose Bournemouth and Poole, i.e. the two towns in the university's conurbation, while the remaining students captured issues and spaces in 12 other cities in six countries, including Barbados, China, Italy, South Africa and Thailand, in addition to several UK towns and cities. One limitation of this approach is that it does not allow the analysis to focus exclusively on a single locality, which might enhance its depth and our understanding of local issues. However, it does mean that participants engaged with communities that they cared and were knowledgeable about. Beyond the confines of this particular pilot, the approach presented here would be particularly valuable in engaging marginalized and 'hard to reach' youth, rather than more media savvy university students.

\section{Findings}


Perhaps the most striking pattern was that half of the participants focused on issues and problems relating to the economy: from unemployment, poverty, inequality and homelessness to conglomeration and the effect that has on local businesses to abandonment, deindustrialization and globalization. Despite the oral and written prompts given before the exercise, and the obvious specificity of the photo, their emphasis was not on particular spatial or aesthetic aspects of the urban landscape - i.e. specific amenities or issues of planning and design, but rather on broader current affairs - such as the global recession and unemployment - that they felt affected them directly. For example, one participant wrote:

We live in cities that are essentially clones of each other. There is no longer room for diversity. We are mere replicas of the inhabitants of the neighbouring towns and cities. We wear the same clothes, eat at the same restaurants and drink at the same coffee houses... The possibility of independence is now just a fabrication of our imagination [P16].

Another, describing her photo, which is shown in Figure 1, pointed out:

I feel like the traditions of the past, my families past [sic], are being left to ruin or destroyed. My photograph depicts one of the most bountiful industries of Hartlepool's past, the steel works. Closed down in 1977, with the loss of 1500 jobs. It's now a backdrop of the town, 'the old steely' a talking point and a memory of what once was [P36].

In the entire sample there were only four indirect (and negative) references to beauty of any sort. Visual representations of public space were very narrow mostly limited to pavements (48.7\% of all public space occurrences) and streets $(34.2 \%)$. There were very few references to civic spaces, such as libraries, monuments and parks, or to distinctive features of urban culture, such as coexistence, diversity, movement and innovation. 


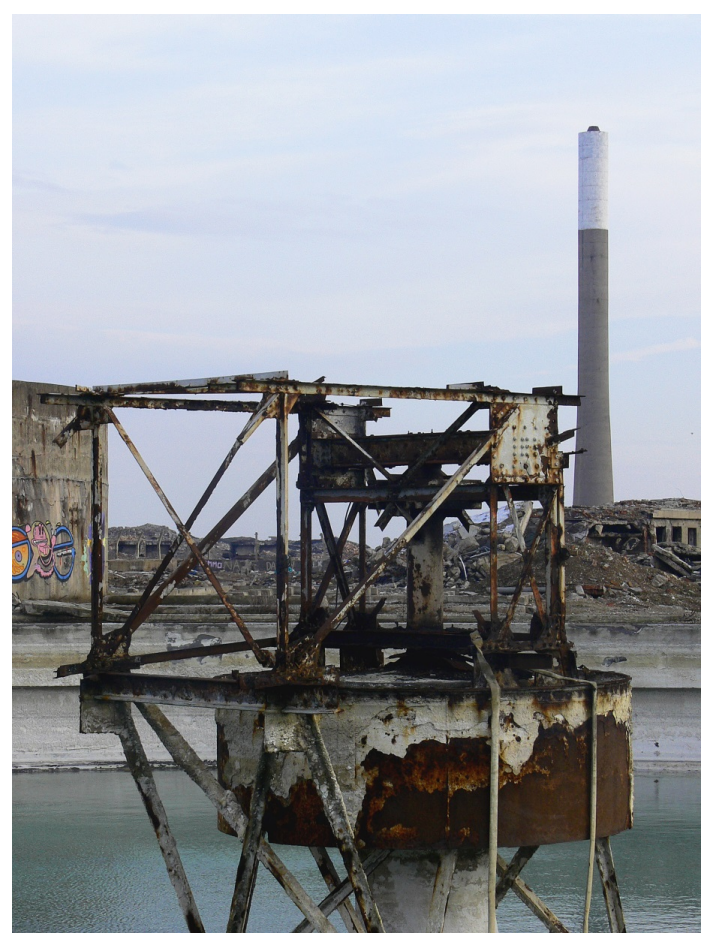

Figure 1. Durham - Industry (by Jessica Gibson, used with permission)

While there was some variety in the angles and topics chosen (especially for nonUK cities), the typical urban landscape depicted in the photos is quiet (51\%), empty $(47.1 \%)$ and, to a lesser extent, dirty (35.3\%). These visual representations were mirrored in the written reflections which were predominantly about dereliction, unemployment and decline. For example, in writing about Figure 2, one student noted:

The unkempt buildings, I noticed, seemed to be mainly in the area surrounding Bournemouth centre as well as dotted around Winton high street. This seems to be where most of the small businesses are placed, rather than big chains, which could provide an explanation as to why they have failed and been left abandoned. The question is however, why are they still there? The unused buildings could be put to use as new shops, businesses or even space for Bournemouth students to set up their own companies [P10].

All of the participants used the reflective piece to talk about their chosen issues, causes and solutions, and a majority (28/51) included some description of what was shown on the photo. Yet, less than half (18/51) contextualised their photo in terms of referring to the process of taking it, and only in less than a fifth $(8 / 51)$ was there a direct or indirect reference to the process of taking the photo sparking an idea or observation (such as "it was shocking to see how many shops were closed down and empty" [P13]). Therefore, coupled with the themes that students engaged with we can infer that, rather than focusing their camera lens on a 
specific spatially-located issue, most students used the photographed setting as an example or symptom of mostly macro-social trends or of the general condition of cities. In other words, their priority was not to highlight spaces that were meaningful to them locally, but to articulate voice for broader political debates. In writing about Figure 3, one student noted:

[The domination of big supermarkets] leads to the 'ghost town effect' that is clearly evident here. Another side-effect of this type of business take-over is that towns and cities lose their character and end up all looking the same [P35]

But then, as Breitbart (1995: 47) notes issues such as the diminishing quality of urban environments "are not necessarily rooted in spatial design [...] They are the product of social, political, and economic forces whose symptoms simply manifest themselves in the compromised physical quality of the built environment". Several students focused on the issue of homelessness, perhaps because it is one of the most visible social problems in urban environments. Their reflective pieces were nuanced insofar as the root causes of the problem are concerned:

Many who fled to rural areas at that time attempted over the years since to integrate themselves back into the cities. Unfortunately many completely lack education and struggle to find work and therefore cannot afford housing and sanitation, it is a vicious cycle [P34]. 

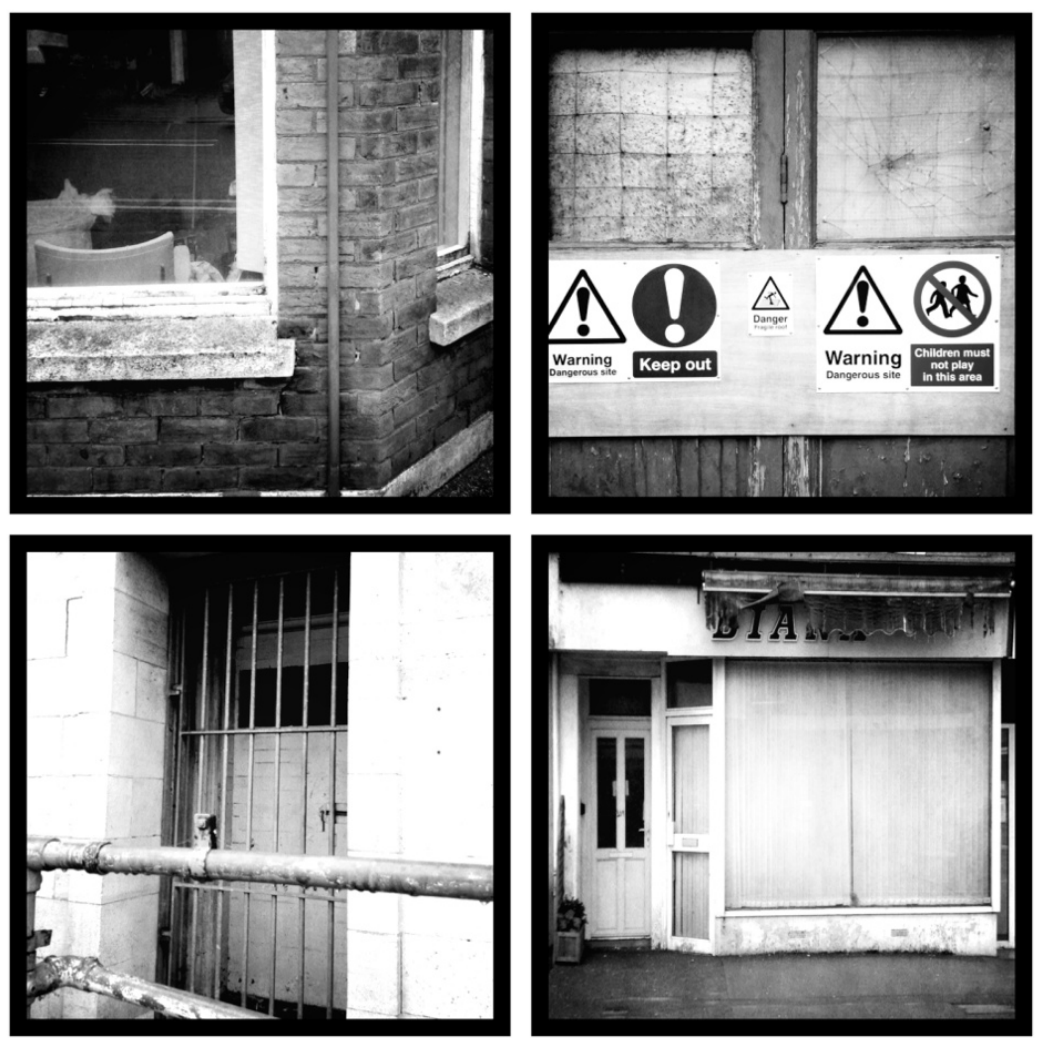

Figure 2. Bournemouth - Dereliction (by Sophie Clements, used with permission)

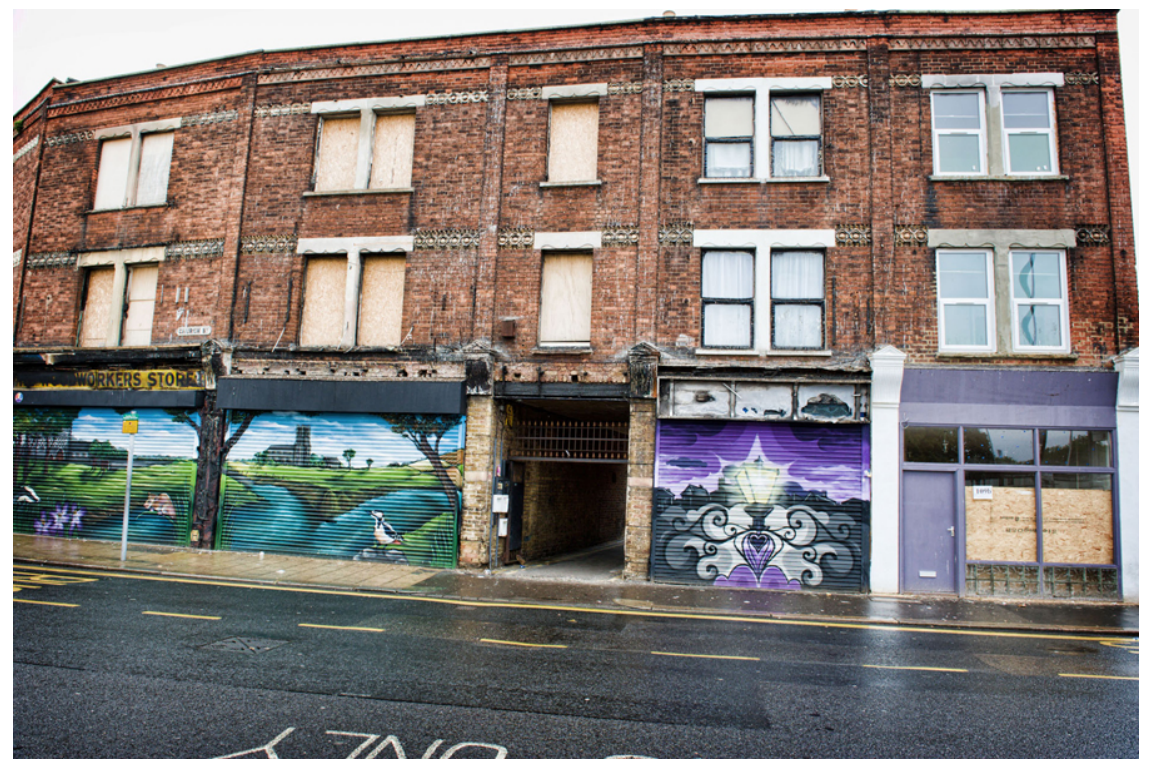

Figure 3. Croydon - Retail (by Georgia Barnes, used with permission)

Almost half of the participants $(22 / 51)$ discussed either existing or potential interventions so as to address the challenges mentioned; these ranged from citing 
specific local schemes to (more often) expressing quite abstract wishes for a solution to the problem.

However, it was also clear that some students viewed their local community, and often space itself, through the lens of mediated discourses. A recurring theme in the reflective pieces was a negative perception - occasionally extending to fear of media and their role in society, revealing an underlying technological determinism: media were seen as all-powerful and overwhelmingly manipulative. One student wrote:

Subliminal messaging may help too, the media is notorious for using subliminal messages to sell ideas to people, and therefore they can use this technique to push people from supporting urbanization [P44].

Another pointed out:

I think the media can hinder the problem of homelessness; newspapers accompanied by biased images rarely portray the homeless in a positive light and regularly associate them with drugs, alcohol abuse and poor sanitation [P17].

Demonstrating awareness of media's role in agenda setting, one student wrote:

Little is being done to address this problem [junk food stores], primarily as the media have, as yet, failed to acknowledge that this is any problem whatsoever [P13].

Few thought of media as possible agents or means of positive urban or social change, and even less referred to specific ways of utilizing media as part of community engagement campaigns. This further highlights the importance of digital and media literacy as its aim is not just to make students critically aware of media frames and representations, but - crucially - to re-emphasize the agency of individuals and social structures (as opposed to a simplistic view of technology) and to enable them to use media and digital information and communication technologies as tools of change. After all, "critical awareness is not enough on its own and can, in fact, act as a double-edged sword. If such opportunities for meaningful participation are lacking, awareness can lead to withdrawal and apathy rather than empowerment" (Gerodimos, 2012: 224).

Some students incorporated common media frames into their analyses of culprits and victims. Their argumentation was predominantly based upon national and transnational concerns and debates, as opposed to local ones, even if the problem being discussed was locally situated (as in: "[Homelessness is] a colossal issue worldwide and with the recent economic crisis hitting it the UK, like an untreated virus, the problem will only continue to escalate" [P14]). 
Another key pattern noted was that the discourse used by participants - and the frame of thinking behind that discourse - was essentially consumerist. The issues raised, the human activities described, the spaces highlighted often focused on shopping or consumption (in fact all but one of the 'everyday routines' identified in the sample were either about shopping or money). For example, consider the way shopping is described by these two students:

The introduction of large supermarkets such as Tesco has allowed the consumer to do all their shopping in one place. The idea of convenience definitely has had a negative impact on [small] businesses, but another major factor is price [P9].

I personally prefer shopping online because of this as do most of my friends, but I'm sure the local business and restaurant owners would much prefer the public walking past their shops and making purchases [P12]

Many students engaged with the issue of small or independent shops going out of business; brands, advertising or commercial signs were the subject of 20 photographs. That is not to say that all of them willingly accepted the role of a consumer, let alone a passive one, but it was evident that they almost felt trapped in a web of urban, social and economic constraints ("Anywhere you just want to sit and enjoy the weather, a cup of tea or a chat with a friend, the common question 'where?' will arise, without having to pay a cost" [P38]).

Overall, it would be fair to say that students' photos and narratives reflected a sense of civic (and subsequently urban) loneliness. This was evident (a) in the ways that they chose to frame urban landscapes visually (focusing on empty, derelict buildings and quiet, dirty streets), (b) in the ways they saw themselves as alienated individuals who lack civic agency to produce meaningful social change, and (c) in their interpretations of the urban condition as something by definition threatening and negative. One student's poignant passage, in commenting on Figure 4, notes:

Look deeper and you'll see that there is a lonely and divided feel to the image, which in turn represents the loneliness that inner city dwellers may experience [P41]. 


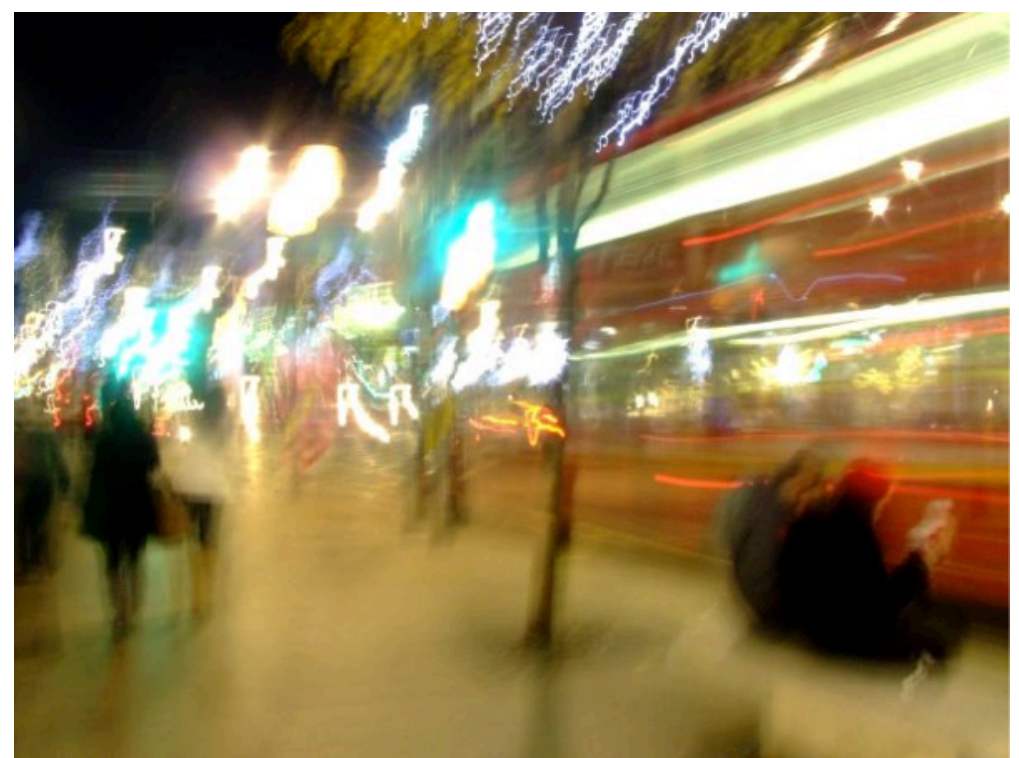

Figure 4. London - Divide (by Anushka Naidoo, used with permission)

Participants' conceptualization of civic action was firmly rooted in a paradigm of liberal individualism and "choice" as opposed to civic duty, responsibility or membership of a collective body politic. Perhaps as a result of that, these young people felt strikingly powerless: their aspirations, hopes, sense of efficacy, existing and emerging priorities, in other words the horizon of their perspective was limited to observing a reality that is uncomfortable and unfair, and an urban landscape that is set in stone, as opposed to imagining and attempting to describe emergent phenomena that could lead to an alternative reality, and considering themselves as part of that change. One student wrote:

Does anyone really care what happens? I fear for my city in the future, but what strikes me is how the people stay smiling, just look at the kids in the photo [P34, referring to smiling children running along a stretch of road in a poor neighborhood of Cape Town].

It is a striking paradox that in an era of unprecedented global digital interconnectivity and virtually limitless technological potential, these young people (on the higher end of the media literacy scale) felt disempowered and disconnected from place and agency.

Naturally, due to the nature of the research, it is possible that students participating in this study may have inadvertently shaped their narratives according to their perceptions of the instructor's expectations. However, the fact that the assignment was voluntary and ungraded, as well as that it took place during the first two weeks of the course meant that there had been limited interaction between the instructor and the cohort. In fact, if anything, the thematic angles from which students approached the exercise - i.e. their focus on the socioeconomic aspect of challenges, as opposed to the more spatial, architectural, historical or aesthetic ones, and the overwhelming critique of media, as opposed to a more forward-looking perspective of how media can also act as tools of 
positive change - diverged from what I might have expected to be the scope of this study. On the one hand, this reaffirmed a 'knowledge gap' with regard to young people's own values and priorities, which acts as a reminder of the need to approach this pedagogy with an open mind and give participants the space to articulate their civic voice, something which can be applied in multiple pedagogic contexts. On the other hand, it poses an interesting challenge for media educators: that of not only empowering students to be critical towards media structures and discourses, but also to be critical towards those critiques, so as to move towards utilizing media for positive social change.

\section{Concluding Reflections}

The relationship between young people and the urban landscape has faced a number of challenges in recent times. Many studies have documented how contemporary configurations of space and social control have contributed to the marginalization of youth. Digital media have provided young people with a safe space for exploration and play, yet constant connectivity and heavy use of digital devices seems to have further disconnected them from the physical surroundings of their city. As cities undergo an era of profound transformation it is more important than ever for young people to become active stakeholders in their own communities, which can in turn provide them with valuable resources, such as social and cultural capital. In this paper I have argued for an approach that brings together urban, youth and media studies so as to both explore and encourage youth engagement with public space. Utilizing tools and approaches borrowed from digital media literacy and participatory photography, I presented a model of pedagogy and research that is on the one hand grounded in debates around place, urban coexistence and the future of cities, and on the other hand it views the city through young people's own eyes (or camera lenses). This micro-social perspective does not overlook the critical importance of collective social agency, i.e. the fact that each individual's voice and power is finite. On the contrary, it allows us to examine how individuals understand and engage with such collective processes and rituals in the context of urban landscapes. An original framework combining both structured variables and a more qualitative interpretation was designed for the coding and analysis of the associated images and reflections produced by participants.

No coding scheme or analytical framework is flawless. Both quantitative/structured and qualitative/interpretive approaches to visual data have specific limitations (which is why combining them can help extract richer data). However, this is the first known visual analysis framework of photographs taken by youth participants in the context of urban and media studies. The framework is presented here so as to encourage transparency and stimulate debate, and is highly adaptable depending on the precise nature of the activity or research project.

A pilot application of this framework revealed the potential that mindful engagement can enable youth to exercise their civic voice. Despite the small and exploratory scale of the project, rich insights - both visual and textual - were produced. This study's participants focused on issues of economic growth, 
employment and sustainability (or lack of), as opposed to more site-specific issues. Class divides, homelessness, urban decay and, in particular, the decline of small businesses were highlighted by many students. Despite their being at the heart of a global youth culture as 'digital natives', globalization emerges as somewhat of a phantom menace for many of them. Issues of structural inequality, lack of control and loss of local identity are central to their concerns. These patterns may not be totally unrelated to Britain's recent decision to leave the European Union as protectionist and anti-globalization forces have gained influence nationally and internationally.

Crucially, and from a media literacy perspective, students' perception of media was overwhelmingly negative and to an extent their analyses were technologically deterministic. As these were students in a media school - and, thus, probably more literate in debates around media ecologies and effects, this raises the question of whether media literacy should counterbalance the extensive deconstruction and criticism of media frames and structures with positive examples and avenues of progressive change and empowerment (Gordon and Mihailidis 2016 is such an attempt to collate a census of how civic media can and is making a positive difference). Talking with young people about local, national and global affairs, how these interlink, how they affect them and the urban landscape, and highlighting ways in which their voice can be heard and institutional or civic avenues of contributing to urban change emerges as an important priority. While the study produced valuable insights, this model would be ideal for engaging marginalized and excluded youth. It could also incorporate further components, such as engagement with urban history: "[1]earning to unlock the information contained in the landscape could facilitate an understanding of the causal relationship between past and present" (Mooney Melvin, 2014: 470).

Finally, another recommendation would be to incorporate an element of community work, such as through a creative intervention or volunteering, or working with a local organization on a 'live' brief. Public art, design work, performance, environmental intervention all have multiple benefits both for the community, and for the young people involved, including personal development (e.g. attitude shifts) and expanded political knowledge (e.g. better understanding of inequalities) (Breitbart 1998). Engaging young people through creative work allows them to experience public space, but also to envision change for themselves and for their communities. As online resources and mobile applications create a "a synergistic relationship between information about individuals, social networks and places" (Hardey 2007: 878-9), realising their potential can provide youth with valuable tools to express their voice.

Assuming that we accept the notion of youth empowerment as a legitimate and partly viable goal, then we need to provide young people with multidimensional and multisensory channels to express their own ideas. These may be different from the ideas of architects and urban planners or indeed (as in this case) of researchers. Rather than trying to remove youth from public space, we should "draw attention to their lives and generate opportunities for them to critically assess, revision, and re-create a portion of their neighbourhood environment" (Breitbart 1995: 35). The emergence of a visual culture amongst 
young people, notably through social media such as Instagram, underlines the urgent need for pedagogic research and practice that helps us understand and utilize the civic potential of visual media.

\section{Acknowledgment}

The author would like to thank the organizers of the 'On Cities' research project at the Salzburg Academy on Media \& Global Change and the global virtual gathering at the University of Miami; Dr Justeen Hyde for her advice on photovoice; Ana Alania, Auguste Janutaite and Alma Sofie Edlund for their assistance with the research. Short segments of this study were included in the short film 'A Certain Type of Freedom' (2015, http://www.vimeo.com/gerodimos/freedom).

\section{References}

Atkinson, R. (2003). Domestication by cappuccino or a revenge on urban space? Control and empowerment in the management of public spaces. Urban Studies, 40, 1829-1843.

BBC News (2011). Teenagers 'should challenge use of mosquito devices'. $B B C$ News, 20 December 2011. Available at: http://www.bbc.co.uk/news/ukpolitics-16273076

Bell, P. (2012). Content analysis of visual images. In J. Hughes (Ed.), Sage Visual Methods (pp. 31 - 58). London: Sage, 31-58.

Bock, A, Isermann H and Knieper T. (2012). Quantitative content analysis of the visual. In: J. Hughes (Ed.), Sage Visual Methods (pp. 313 - 334). London: Sage.

Bovill, M. and Livingstone, S. (2001). Bedroom culture and the privatization of media use. In: S. Livingstone and M. Bovill (Eds.), Children and their changing media environment: a European comparative study. . Mahwah, N.J., USA: Lawrence Erlbaum Associates.

Breitbart, M. (1995). Banners for the street: Reclaiming space and designing change with urban youth. Journal of Planning Education and Research, 15: 35-49.

Breitbart, M. (1998). “Dana's Mystical Tunnel”: Young people's designs for survival and change in the city. In T. Skelton and G. Valentine (Eds.), Cool places: Geographies of youth cultures (pp. 305 - 327). Routledge: London.

Brown, DM (2013). Young people, anti-social behaviour and public space: The role of community wardens in policing the 'ASBO Generation.' Urban Studies, 50(3), 538-555.

Burden, A (2014). How public spaces make cities work, TED Talk, available at https://www.ted.com/talks/amanda_burden_how_public_spaces_make_citi es_work

Chalfen, R. (2011). Differentiating practices of participatory visual media production. In E. Margolis and L. Pauwels (Eds.), The SAGE handbook of visual research methods (pp. 186 - 200). London: Sage. 
Clark-Ibanez, M. (2007). Inner-city children in shaper focus: Sociology of childhood and photo elicitation interviews in G. C. Stanczak (Ed.), Visual research methods: Image, society, and representation (pp. 167 - 198). London: Sage.

Collins, D. and Kearns, R. (2001). Under curfew and under siege? Legal geographies of young people. Geoforum, 32(3), 389-403.

Frank, K. (2006). The potential of youth participation in planning. Journal of Planning Literature 20(4), 351-371.

Friedman, A. (2016). Three-year-pld photographers: Educational and parental mediation as a basis for visual literacy via digital photography in early childhood. Journal of Media Literacy Education, 8: 1, 15-31.

Friesem, E. (2014). A story of conflict and collaboration: Media literacy, video production and disadvantaged youth. Journal of Media Literacy Education, 6(1), 44-55.

Gerodimos, R. (2012). Online youth civic attitudes and the limits of civic consumerism: The emerging challenge to the Internet's democratic potential. Information, Communication \& Society, 15(2): 217-245.

Gerodimos, R. (2016). From "being tethered" to "going unplugged": media addiction and the role of unplugging as a transformative tool of digital literacy. In B. De Abreu, P. Mihailidis, A. Lee, J. Melki and J. McDougall (Eds.), The international handbook of media literacy education. London: Routledge.

Giroux, H. (2011). The crisis of public values in the age of the new media. Critical Studies in Media Communication, 28: 8-29.

Gordon, E. and Koo, G. (2008). Placeworlds: Using virtual worlds to foster civic engagement. Space and Culture, 11(3): 204-221.

Gordon, E. and Mihailidis, P. (2016). Civic Media: Technology, Design, Practice. Cambridge, MA: MIT Press.

Gotschi, E. Delve, R. and Freyer, B. (2009). Participatory photography as a qualitative approach to obtain insights into farmer groups. Field Methods 21(3): 290-308.

Gough, K. and Franch, M. (2005). Spaces of the street: socio-spatial mobility and exclusion of youth in Recife. Children's Geographies, 3(2): 149-166.

Gubrium, A. and Harper, K. (2013). Participatory visual and digital methods. Walnut Creek, CA: Left Coast Press.

Hardey, M. (2007). The city in the age of web 2.0 a new synergistic relationship between place and people. Information, Communication \& Society, 10: 6: 867-884.

Harper, D. (2002). Talking about pictures: A case for photo elicitation. Visual Studies, 17: 13-26.

Henthorn, T. (2014) Experiencing the city: Experiential learning in urban environments. Journal of Urban History, 40(3): 450-61.

Hughes, J. (Ed). (2012). Sage visual methods. London: Sage.

Humphreys, L. (2010). Mobile social networks and urban public space. New Media \& Society, 12(5): 763-778. 
Katz, C. (1998). Disintegrating developments: Global economic restructuring and the eroding ecologies of youth. In: T. Skelton and G. Valentine (Eds.), Cool places: geographies of youth cultures (pp. 133 -144). London: Routledge.

Kesby, M. (2007). Spatialising participatory approaches: the contribution of geography to a mature debate. Environment and Planning, 39: 2813-2831.

Laughlin, D. and Johnson, L. (2011). Defining and exploring public space: perspectives of young people from Regent Park, Toronto. Children's Geographies, 9(3-4): 439-456.

Leander, K.M., Phillips, N.C. and Headrick, Taylor K (2010). The changing social spaces of learning: Mapping new mobilities. Review of Research in Education, 34: 329-394.

Leyshon, M., DiGiovanna, S. and Holcomb, B. (2013) Mobile technologies and youthful exploration: Stimulus or inhibitor? Urban Studies, 50(3): 587605.

Livingstone, S. (2005). In defence of privacy: mediating the public/private boundary at home. In S. Livingstone (Ed.), Audience and publics: When cultural engagement matters for the public sphere (pp. 163 - 187). Bristol: Intellect Books.

Lofland, L.H. (1998). The public realm: Exploring the city's quintessential social territory. New York: Aldine de Gruyter.

Malone, K. (2002). Street life: Youth, culture and the competing uses of public space. Environment and Urbanization, 14: 157-168.

Margolis, E. and Pauwels, L. (eds) (2011) The SAGE handbook of visual research methods. London: Sage.

Massey, D. (1998). The spatial construction of youth cultures. In T. Skelton and G. Valentine (Eds.), Cool places: geographies of youth cultures (pp. 121 129). London: Routledge.

Matthews, R., Limb, M. and Taylor, M. (2000) The street as “thirdspace.” In S. L. Holloway and G. Valentine (Eds.), Children's geographies: Playing, living, learning (pp. 63 - 79). London: Routledge.

Meringolo, D.D. (2014) The place of the city: Collaborative learning, urban history, and transformations in higher education. Journal of Urban History, 40(3): 419- 424.

Mihailidis, P. and Gerodimos, R. (2016) Connecting pedagogies of civic media: The literacies, connected civics, and engagement in daily life. In E. Gordon and P. Mihailidis, (Eds.), Civic media: Technology, design, practice (pp. 371-391). Cambridge, MA: MIT Press.

Mihailidis, P. and Thevenin, B. (2013) Media literacy as a core competency for engaged citizenship in participatory democracy. American Behavioral Scientist. 57(11), 1611-1622. doi: 10.1177/0002764213489015

Mooney-Melvin, P. (2014) Engaging the neighborhood: The East Rogers Park Neighborhood History Project and the possibilities and challenges of community-based initiatives. Journal of Urban History, 40(3): 462- 478.

Orellana, M. (1999). Space and place in an urban landscape: learning from children's views of their social worlds. Visual Sociology,14 (1-2): 73-89. 
Paradise, A.M. (2011). Bridging service-learning with media literacy: Creating contexts for communication students to educate youth on media content, consumption, and effects. Communication Teacher, 25(4): 234-239.

Pauwels, L. (2011). An integrated conceptual framework for visual social research. In E. Margolis and L. Pauwels (Eds.), The SAGE handbook of visual research methods (pp. 3 - 23). London: Sage.

Samuels J (2007) When words are not enough: Eliciting children's experiences of Buddhist monastic life through photographs. In G. Stanczak (Ed.), Visual research methods (pp. 197 - 224). London: Sage Publications.

Schiller, J. and Tillett, B. (2004). Using digital images with young children: challenges of integration. Early Child Development and Care, 174: 401414.

Sheehy, M. (2004) Between a thick and a thin place: Changing literacy practices. In K. Leander and M. Sheehy (Eds.), Spatializing literacy research and practice (pp. 91 - 114). New York: Peter Lang.

Skelton, T. (2013) Young people's urban im/mobilities: Relationality and identity formation. Urban Studies, 50(3): 467-483.

Skelton, T. and Valentine, G. (eds) (1998) Cool places: geographies of youth cultures. London: Routledge.

Skelton, T. and Gough, K.V. (2013). Introduction: Young people's im/mobile urban geographies. Urban Studies, 50(3): 455-466.

Stanczak, G. C. (Ed.) (2007). Visual research methods: Image, society, and representation. London: Sage.

Tunstall, S, Tapsell, S. and House, M. (2004) Children's perceptions of river landscapes and play: what children's photographs reveal. Landscape Research, 29(2): 181-204.

Turkle, S. (2011). Alone together. New York, NY: Basic Books

Wang, C.C., Morrel-Samuels, S., Hutchison, P., Bell, L. and Pestronk, R.M. (2004) Flint photovoice: Community building among youths, adults, and policymakers. American Journal of Public Health, 94(6): 911-13.

Weinstein, A. and Lejoyeux, M. (2010), Internet addiction or excessive internet use? The American Journal of Drug and Alcohol Abuse, 36(5): 277-283.

Wilken, R. (2008). Mobilizing place: Mobile media, peripatetics, and the renegotiation of urban places. Journal of Urban Technology, 15(3): 39-55.

\section{Acknowledgements}

The author would like to thank Sanjeev Chatterjee, Susan Moeller, Megan Fromm and Paul Mihailidis for organising the On Cities research project at the Salzburg Academy on Media \& Global Change and the global virtual gathering at the University of Miami. The author thanks Justeen Hyde for her advice on photovoice, Ana Alania, Auguste Janutaite and Alma Sofie Edlund for their assistance with the research, and the two anonymous referees for their helpful suggestions. Short segments of this paper were previously included in the script for the short film, entitled, A Certain Type of Freedom. http://www.vimeo.com/gerodimos/freedom 